\title{
Analysis of the Trip Effect by Means of Axisymmetric Compressive Tests on a Si-Mn Bearing Steel
}

\author{
Abdellah AIROD, Roumen PETROV, Rafael COLÁS ${ }^{1)}$ and Yvan HOUBAERT \\ Department of Metallurgy and Materials Science, Ghent University, Technologiepark 903, B-9052 Gent, Belgium. \\ 1) Facultad de Ingeniería Mecánica y Eléctrica, Universidad Autónoma de Nuevo León, A.P. 149-F, 66451 San Nicolás de los \\ Garza, N.L., México.
}

(Received on June 9, 2003; accepted in final form on August 6, 2003)

\begin{abstract}
Analysis of the TRIP-effect has been implemented by means of series of axisymmetric compressive tests on a Si-Mn bearing TRIP-assisted steel heat treated to vary the amount of retained austenite from 5.70 to $9.11 \%$. The cylindrical samples were deformed with true strains of $0.25,0.5$ and 1 , and constant strain rate of $0.1 \mathrm{~s}^{-1}$ at room temperature. Microstructural examination of the samples indicates that most of the deformation is sustained by the weakest phase, ferrite. The stress-strain data was fitted to different constitutive equations to evaluate the point at which the TRIP-effect triggers. The results showed that the amount of retained austenite is reduced with the increase of strain. No complete transformation of austenite was found to occur as a fraction of austenite remains untransformed even at equivalent strains as high as one. The behaviour of samples with different amounts of retained austenite, but of equal carbon content, was found to depend on the volume fraction of this structure. It was found that the TRIP-effect was triggered at lower strains, but higher stresses, as the amount of this phase increased.
\end{abstract}

KEY WORDS: axisymmetric compression; constitutive equations; TRIP steels; microstructure; retained austenite.

\section{Introduction}

In the recent years a lot of investigation have been implemented in the field of the so-called TRIP (TRansformation Induced Plasticity)-assisted steels, because of their attractive combination of high strength and ductility. The TRIPassisted or TRIP-aided steels have complex multiphase microstructures, which consist in general of ferrite, bainite and retained austenite, but in some cases martensite and carbides may be present. Their strength and formability characteristics are obtained in cold rolled steels by subjecting them to a specific two-stage heat treatment that consists of an intercritical annealing stage (between $\mathrm{Ac}_{1}$ and $\mathrm{Ac}_{3}$ ) followed by interrupted isothermal quenching in the bainitic region. This treatment results in a microstructure consisting of ferrite, bainite and islands of retained austenite. The duration of the isothermal treatment in the bainitic region is critical, as a minimum amount of untransformed (retained) austenite is required to achieve the TRIP-effect in the steel. ${ }^{1-5)}$

The functional properties of tensile strengths between 600 and $800 \mathrm{MPa}$, together with a ductility above $25 \%$ of TRIP-assisted steels are determined by a combination of a ferrite matrix, for ductility, bainite, for strength, and an appropriate volume fraction of metastable retained austenite, which, on transformation to martensite during deformation, will provide for the enhancement of ductility. From this point of view, the carbon content and the size, distribution and crystallographic orientation of the retained austenite are the parameters that determine its transformational sta- bility. Enhancement of ductility in TRIP-assisted steels results from the increment in the work hardening rate, which delays the onset of different types of plastic instability (necking being the macroscopic manifestation of such in a tensile test). The increment in strength in these materials is associated with the increase in dislocation density promoted by the change in volume associated with the transformation. $^{1-5)}$

Most of the studies on the mechanical behaviour of the TRIP-effect are carried out in tensile conditions. A recently published work $^{5)}$ establishes that the onset for necking, which is the macroscopic manifestation of strain localization in tension, can be predicted by means of recording the changes on the volumetric fraction of the retained austenite of the steel during deformation. The aim of this work is to study the behaviour of a conventional TRIP-assisted steel with various amounts of retained austenite with different carbon content during deformation at room temperature. The mechanical tests were conducted in axisymmetric compression to take advantage of the higher level of uniform deformation that can be attained in this type of test.

\section{Experimental Procedure}

Cylindrical samples of $15 \mathrm{~mm}$ in height by $10 \mathrm{~mm}$ in diameter were machined from a $\mathrm{Si}-\mathrm{Mn}$ bearing steel $(0.13 \%$ C, $1.24 \% \mathrm{Si}, 1.62 \% \mathrm{Mn}, 0.017 \% \mathrm{P}, 0.003 \% \mathrm{~S}, 0.026 \%$ $\mathrm{Cr}, 0.015 \% \mathrm{Mo}, 0.025 \% \mathrm{Ni}, 0.062 \% \mathrm{Al}, 0.003 \% \mathrm{Nb}$, in weight) that was considered to be adequate to provide the multiphase structure of ferrite, bainite and retained austen- 
ite needed for the TRIP-effect. The specimens were heat treated in salt baths following a two-stage heat-treating cycle. The first one consisted of 4 min intercritical soaking for at either 750 or $800^{\circ} \mathrm{C}$ to promote different mixtures of ferrite and austenite. The second isothermal stage was carried out at either 400 or $450^{\circ} \mathrm{C}$ to promote the partial transformation of the previously formed austenite into bainite. The specimens were left at this temperature for either 2 or 4 min to vary the degree of transformation; the specimens were left to cool down to room temperature on air. The record of the thermal cycle for a sample held at $800^{\circ} \mathrm{C}$ for $4 \mathrm{~min}$ and at $450^{\circ} \mathrm{C}$ for another two is shown in Fig. 1. The temperatures at the centre and surface of the sample were recorded by inserting a chromel-alumel type $\mathrm{K}$ thermocouple to its centre and by welding a second one to its surface, the maximum difference in temperature between these two zones, once the sample has reached the temperature set at both baths, is below $7^{\circ} \mathrm{C}$.

The samples were deformed in axysimmetric compression in a servo-hydraulic computer driven testing machine. Various samples were deformed to different nominal values of strain $(0.25,0.5$ and 1$)$ at room temperature and at a constant strain rate of $0.1 \mathrm{~s}^{-1}$. All the experiments were conducted using $0.1 \mathrm{~mm}$ thick polytetrafluoroethylene (PTFE) tape as lubricant to reduce the frictional conditions at the specimen-tooling interface; examination of the compressed samples showed that the tape behaved as expected. The load-displacement data was converted into stress-strain curves assuming a friction coefficient of 0.05 . Full description of the testing machine and the procedure used to process the data to obtain the stress-strain curves can be found elsewhere. ${ }^{\text {) }}$

The microstructure of the samples before and after deformation was studied by means of light optical microscopy (LOM), scanning electron microscopy (SEM) and orientation imaging microscopy (OIM). The samples were cut trough their centre along a line parallel to the height of the cylinder, the load axis, and were mechanically grinded and polished up to $1 \mu \mathrm{m}$ diamond paste following standard procedures. The specimens for LOM were etched with a colour tint reagent (LePera technique), ${ }^{7,8)}$ whereas those for SEM were etched in a $2 \%$ solution of nitric acid dissolved in methanol. The samples that were selected for the OIM analysis were polished by electrolitical means to assure a damage free surface. OIM is used in combination with SEM to evaluate the local crystal orientation by the analysis of the pseudo-Kikuchi lines that result from electron backscattered diffraction (EBSD). ${ }^{9}$ This analysis can yield to a semi-quantitative evaluation of strain accumulation among the different microstructural components (ferrite, bainite and retained austenite). The orientation data were post processed by means of a proprietary software ${ }^{9)}$ that determines the Image Quality (IQ) factor as well as the distribution of the rotation angle between neighbouring boundaries, which are used to assess the degree of accumulation of strain, as high values of the IQ factor correspond to high contrast in the pseudo-Kikuchi patterns, which is associated to a perfect, undistorded and clear from dislocations, crystal lattice. Consequently, low values of IQ are found in highly deformed material. As result of this, areas of the material free of dislocations will appear as bright, and those deformed will be dark.

The volume fraction of retained austenite was determined by X-ray diffraction (XRD) with $\mathrm{Mo} \mathrm{K}_{\alpha}$ radiation $(\lambda=0.0711 \mathrm{~nm})$ using the direct comparison method. ${ }^{10)}$ The volume fraction was computed from the integrated intensities of two diffraction peaks corresponding to austenite, $\{220\}$ and $\{311\}$, and two from ferrite, $\{200\}$ and $\{211\}$. The $2 \theta$ angular interval of 27 to $39^{\circ}$ was scanned with a step size of $0.01^{\circ}$ with a scanning period of $1.2 \mathrm{~s} /$ per step. The shift of the $\{220\} \lambda$ diffraction peak was used to calculate the lattice parameter of the retained austenite before deformation was applied to the samples:

$$
a_{0}=\frac{\lambda \sqrt{2}}{\sin \theta}
$$

where $\lambda$ takes the value of $\mathrm{MoK}_{\alpha}$. Enrichment of carbon can be calculated from the expansion of this lattice parame$\operatorname{ter}^{11,12)}$ :

$$
\begin{aligned}
& a_{0}=0.3578+0.0033 \cdot[\% \mathrm{C}]+0.000096 \cdot[\% \mathrm{Mn}] \\
& -0.00152 \cdot[\% \mathrm{Si}]
\end{aligned}
$$

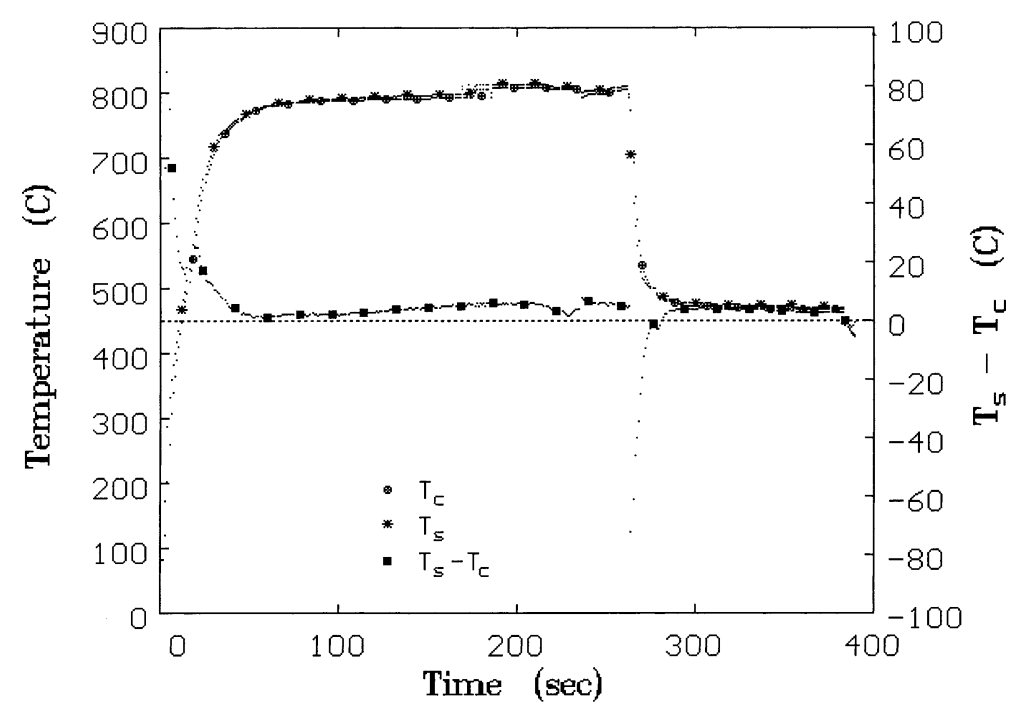

Fig. 1. Thermal cycles recorded by two type $\mathrm{K}$ thermocouples inserted at the centre $\left(T_{\mathrm{c}}\right)$ and welded to the surface $\left(T_{\mathrm{s}}\right)$ of a sample treated at $850^{\circ} \mathrm{C}$ for $4 \mathrm{~min}$ and at $450^{\circ} \mathrm{C}$ for $2 \mathrm{~min}$. 
Table 1. Results from the X-ray diffraction analysis.

\begin{tabular}{ccccccc}
\hline $\begin{array}{c}\text { Sample } \\
\text { identification }\end{array}$ & $\begin{array}{c}\text { Intercritical } \\
\text { temperature } \\
(\mathrm{C})\end{array}$ & $\begin{array}{c}\text { Bainitic } \\
\text { temperature } \\
(\mathrm{C})\end{array}$ & $\begin{array}{c}\text { Bainitic } \\
\text { time } \\
(\mathrm{min})\end{array}$ & $\begin{array}{c}\text { Retained } \\
\text { austenite } \\
(\%)\end{array}$ & $\begin{array}{c}\text { Lattice } \\
\text { parameter } \\
(\mathrm{nm})\end{array}$ & $\begin{array}{c}\text { Carbon } \\
\text { dissolved } \\
(\%)\end{array}$ \\
\hline $\mathbf{A}$ & 750 & 400 & 2 & 5.70 & 0.3605 & 0.817 \\
$\mathbf{B}$ & 750 & 400 & 4 & 5.84 & 0.3609 & 0.931 \\
$\mathbf{C}$ & 750 & 450 & 2 & 7.22 & 0.3608 & 0.833 \\
$\mathbf{D}$ & 750 & 450 & 4 & 7.56 & 0.3608 & 0.899 \\
$\mathbf{E}$ & 800 & 400 & 2 & 6.44 & 0.3608 & 0.915 \\
$\mathbf{F}$ & 800 & 400 & 4 & 7.13 & 0.3615 & 1.111 \\
$\mathbf{G}$ & 800 & 450 & 2 & 9.11 & 0.3606 & 0.833 \\
H & 800 & 400 & 4 & 6.63 & 0.3609 & 0.931 \\
\hline
\end{tabular}

Table 2. Changes in the amount of retained austenite with the amount of deformation.

\begin{tabular}{ccccc}
\hline Sample & \multicolumn{4}{c}{ Strain } \\
identification & 0 & 0.25 & 0.5 & 1 \\
\hline $\mathbf{A}$ & 5.70 & 2.34 & 1.17 & 1.14 \\
$\mathbf{B}$ & 5.84 & 2.05 & 1.89 & - \\
$\mathbf{C}$ & 7.22 & 3.68 & 2.13 & 1.23 \\
$\mathbf{D}$ & 7.56 & 3.70 & 3.23 & 1.12 \\
$\mathbf{E}$ & 6.44 & 3.11 & 2.80 & 1.56 \\
$\mathbf{F}$ & 7.13 & 5.28 & 2.82 & 1.87 \\
$\mathbf{G}$ & 9.11 & 3.43 & 2.82 & 1.59 \\
$\mathbf{H}$ & 6.63 & - & 1.77 & 1.20 \\
\hline
\end{tabular}

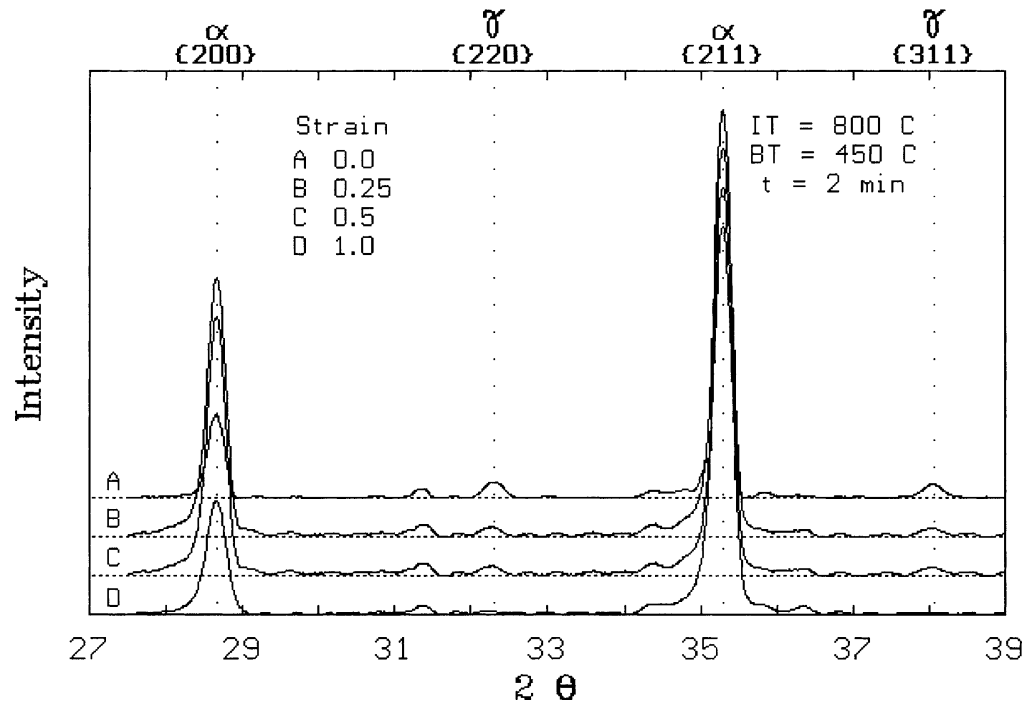

Fig. 2. X-ray diffraction patterns of the samples heat treated at 800 and $450^{\circ} \mathrm{C}$ for 2 min and compressed to various amounts of strain.

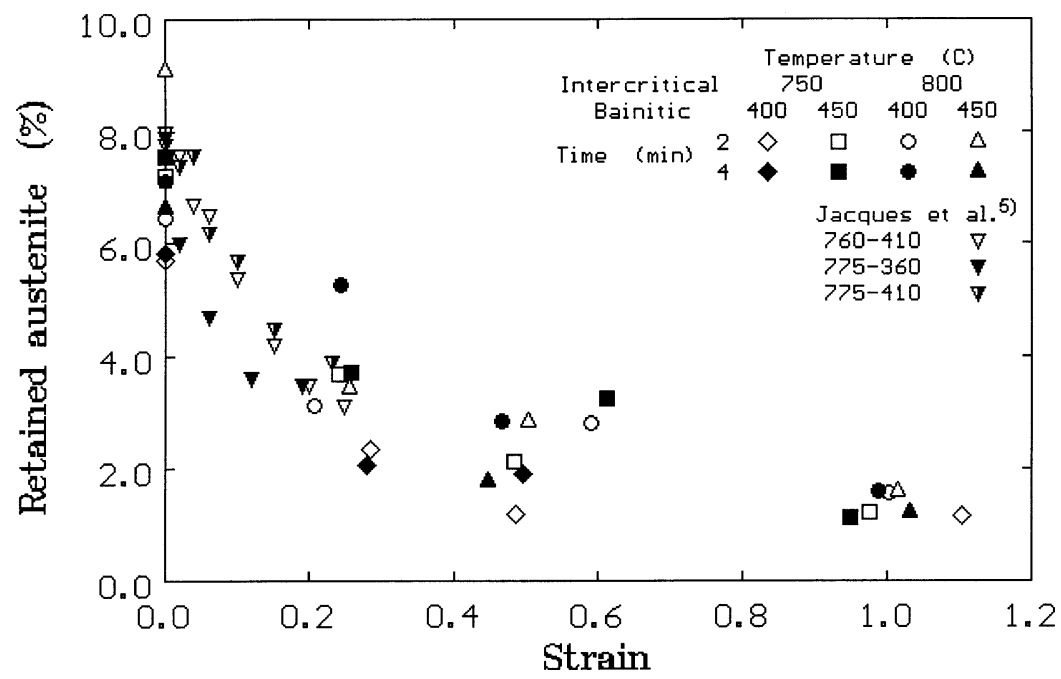

Fig. 3. Variation of the amount of retained austenite as function of strain, data from Ref. 5) are included.

where the dimensions of the parameter are given in $\mathrm{nm}$ and the contents in weight percentage.

\section{Results}

Table 1 shows the amount of retained austenite that was measured by means of XRD. The change in the lattice parameter of austenite and the amount of carbon dissolved within this phase was computed from the shift of the peaks. The analysis of the XRD patterns showed that the amount of retained austenite is reduced with the amount of deformation imparted to the samples. Figure 2 displays the diagrams for specimens that were treated for $4 \mathrm{~min}$ at $800^{\circ} \mathrm{C}$ and $2 \mathrm{~min}$ at $450^{\circ} \mathrm{C}$ and were compressed to different strain levels. Table 2 shows the amount of retained austenite in various samples as a function of the applied strain.

The variation of the retained austenite as a function of compressive strain, together with data from a material with similar composition and heat treatment, but tested in tension, ${ }^{5)}$ is shown in Fig. 3 for comparison. Variation of the 


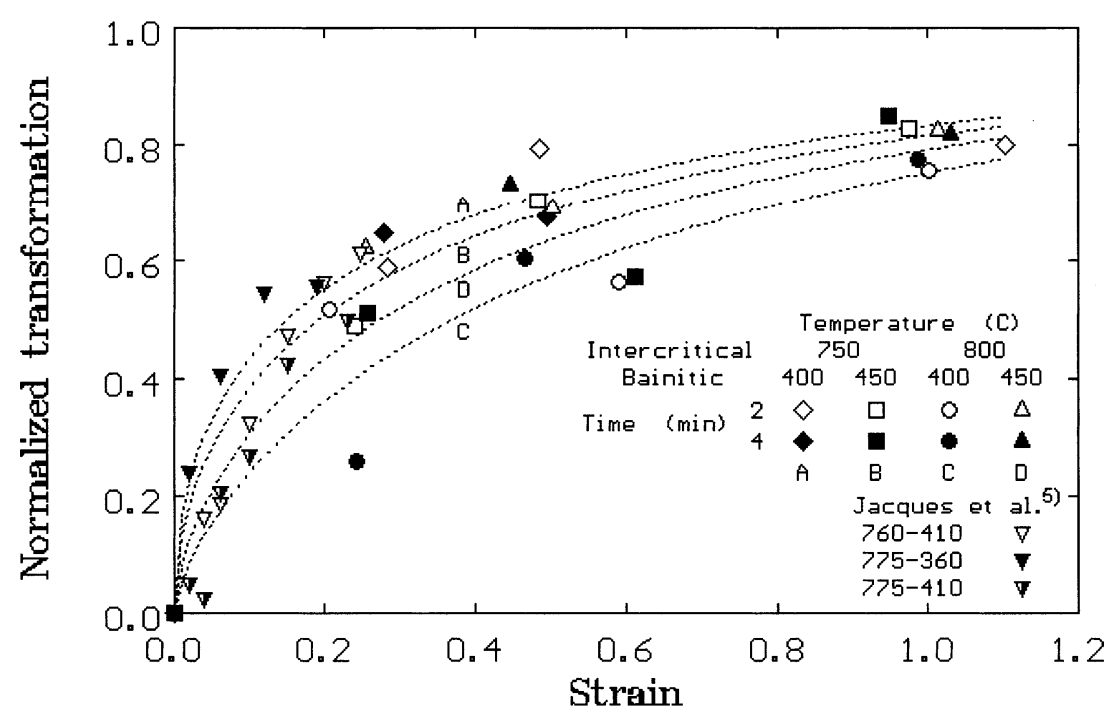

Fig. 4. Variation of the fraction of austenite transformed during deformation.

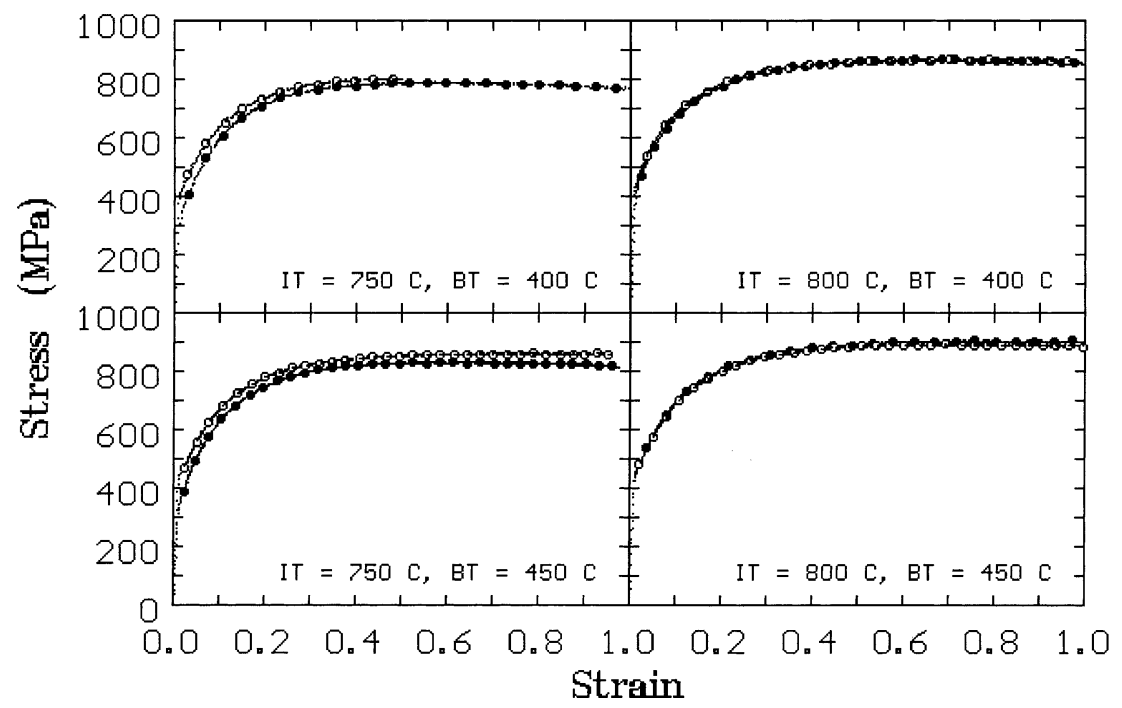

Fig. 5. Stress-strain curves after different heat treatments. IT and BT are the temperatures of the intercritical and bainite stages; the time at BT of 2 and $4 \mathrm{~min}$ are indicated by full and open circles respectively.

normalized transformation of the retained austenite as a function of strain is plotted in Fig. 4. Four dotted curves (identified as A to D) show the variation of the transformed fraction for the combination of the intercritical and bainitic temperatures. The transformed fraction was calculated as:

$$
X=\frac{\gamma_{\mathrm{o}}-\gamma_{\varepsilon}}{\gamma_{\mathrm{o}}}
$$

where $X$ is the normalized transformed fraction and $\gamma_{\mathrm{o}}$ and $\gamma_{\varepsilon}$ are, respectively, the amounts of retained austenite in unstrained and strained conditions (see Table 2).

Figure 5 shows the stress-strain curves obtained from the load-displacement data assuming a friction coefficient of 0.05. ${ }^{6}$ All the curves show a continuous increase of strength up to a constant level of stress (saturation). The strength of the material increases with the increment of the temperature of the intercritical soak as well as the bainitic hold temperature. The time at the bainitic stage seems to affect the strength only when the intercritical soaking was carried out at $750^{\circ} \mathrm{C}$.
Microscopic examination of unstrained and deformed samples may indicate that deformation is concentrated in ferrite. Figure 6 shows the microstructures of the sample identified as $\mathbf{G}$ in Table 1, which is the one with the highest amount of retained austenite after heat treatment. The microstructures were prepared from unstrained specimens and from samples deformed to an equivalent strain of one; Fig. 7 shows the corresponding OIM images obtained from the same specimens that are shown in Fig. 6. The various microstructural components are identified in these two figures. The direction of axial compression in Figs. 6(c) and 6(d), and in Fig. 7(b) is the vertical one.

A characteristic feature of samples A (with low retained austenite) and $\mathbf{G}$ (with high amount of retained austenite) is that the carbon content of the austenite is almost the same, 0.82 and $0.83 \%$, respectively, therefore, the temperatures at which transformation from austenite to martensite in nonstrained conditions $\left(\mathrm{M}_{\mathrm{s}}\right)$ should be also equal or at least should differ in only a small amount. The latter open a possibility to compare the influence of the stress or strain state on the transformation behaviour of the TRIP-assisted steel, 

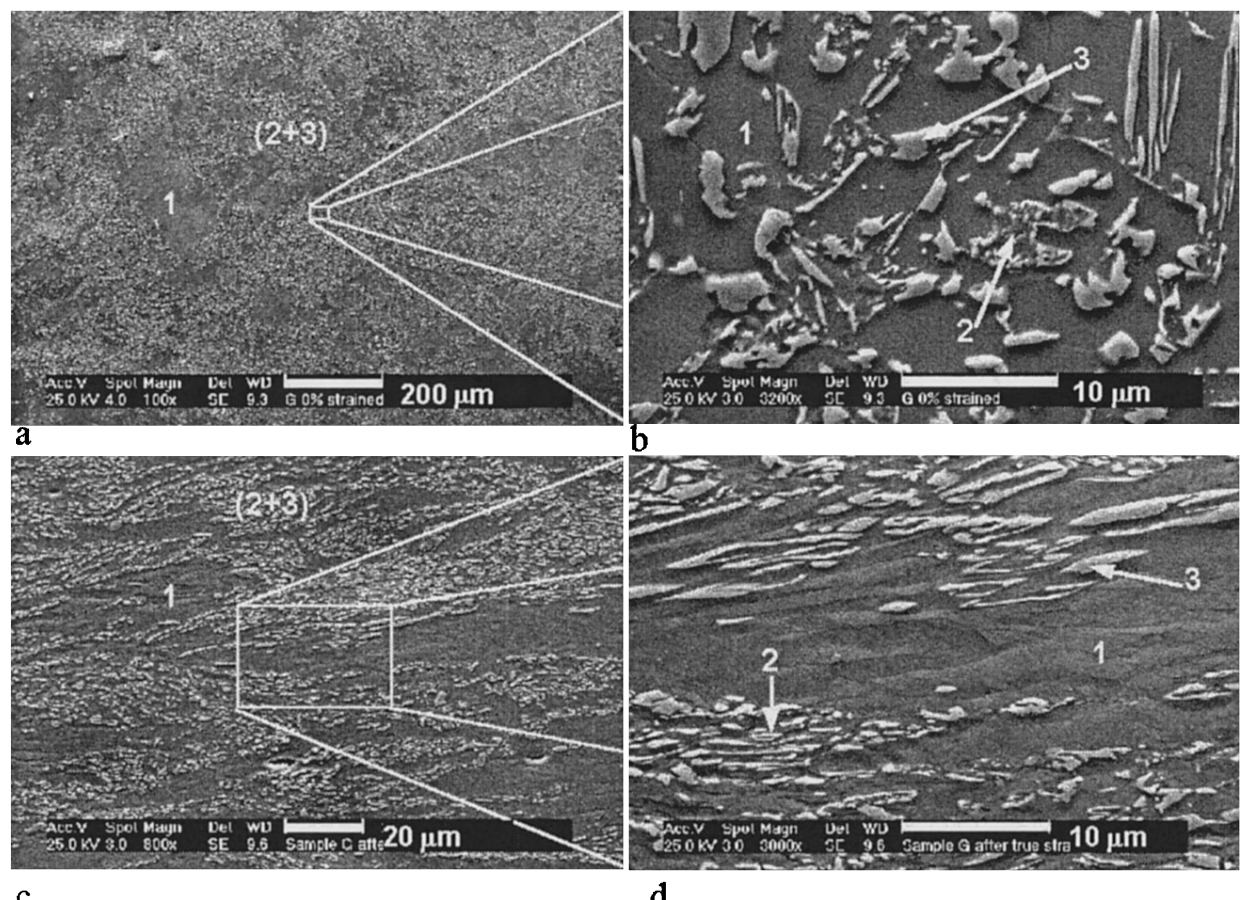

c

d

Fig. 6. SEM images of sample G before deformation (a), (b) and after an equivalent strain of one was imparted (c), (d); ferrite is identified as 1 , bainite as 2 and the mixture of either martensite or austenite as 3 . The direction of compression is the vertical one.

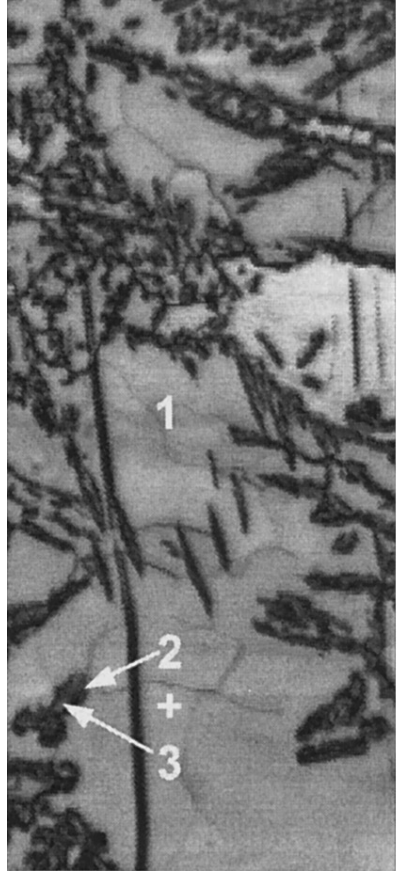

$12.50 \mu \mathrm{m}=25$ steps

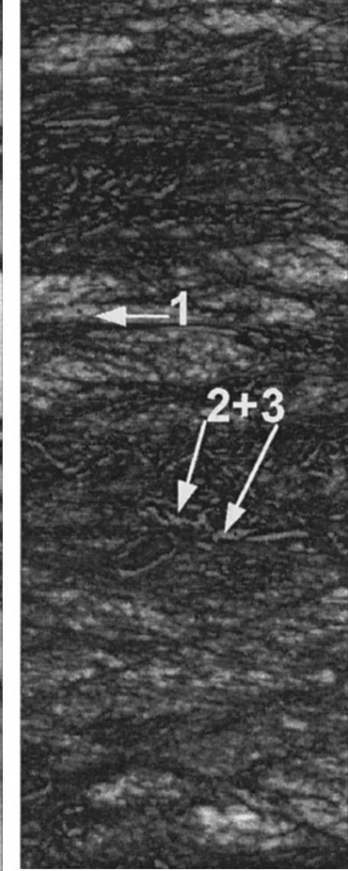

$10.50 \mu \mathrm{m}=35$ steps

Fig. 7. OIM images of sample $\mathbf{G}$ before deformation (a) and after an equivalent strain of one was imparted (b), the microstructural components are identified as in the Fig. 6. The direction of compression is the vertical one.

because the amount of martensite transformed from the retained austenite will only depend on the amount of deformation, not on the chemical composition.

\section{Discussion}

It can be seen in Fig. 2 that the peaks corresponding to

retained austenite diminish with the increase of strain, which implies its transformation into a more stable structure. The angular $(2 \theta)$ position of the austenite $\{220\}$ and (311\} peaks in Fig. 2 are 32.205 and $38.078^{\circ}$, respectively, which are smaller than the expected values of 32.42 and $38.22^{\circ}$ for unalloyed austenite with the diffraction conditions used. ${ }^{10)}$ Such shift will be caused by a FCC structure with a lattice parameter $\left(a_{0}\right)$ of $0.3606 \mathrm{~nm}$, from which the carbon content of $0.833 \%$ is calculated.

The four dotted lines, which are shown in Fig. 4, (one for each of the four combinations of two soaking and two bainitic temperatures) display how the volume fraction of retained austenite changes with deformation. It can be seen that most of the austenite transforms at an early stage of deformation, although some austenite remains untransformed even at strains as high as one, data from tensile tests ${ }^{5}$ indicate that the material follows a similar behaviour, independently of the different deformation path.

Constitutive equations are used to describe the changes in strength that take place in deformed materials. These relationships are empirical and relate changes in strength produced from variation in strain, temperature or strain rate. The most common equations are derived from the power relationship proposed by Ludwik in $1909^{13)}$ :

$$
\sigma=\sigma_{\mathrm{o}}+k \cdot \varepsilon^{n}
$$

where $\sigma$ and $\varepsilon$ are, respectively, the instantaneous values of real stress and real strain. $\sigma_{0}$, the yield stress, $k$, the strength coefficient, and $n$, the strain-hardening exponent, are calculated from experimental flow curve. Other authors $^{14,15)}$ have modified Eq. (4) to obtain better fitting of experimental data.

The fit of power relationships such as that given by Eq. (4) is only accurate within limited ranges of strain, since these equations tend to underestimate the stress close to 


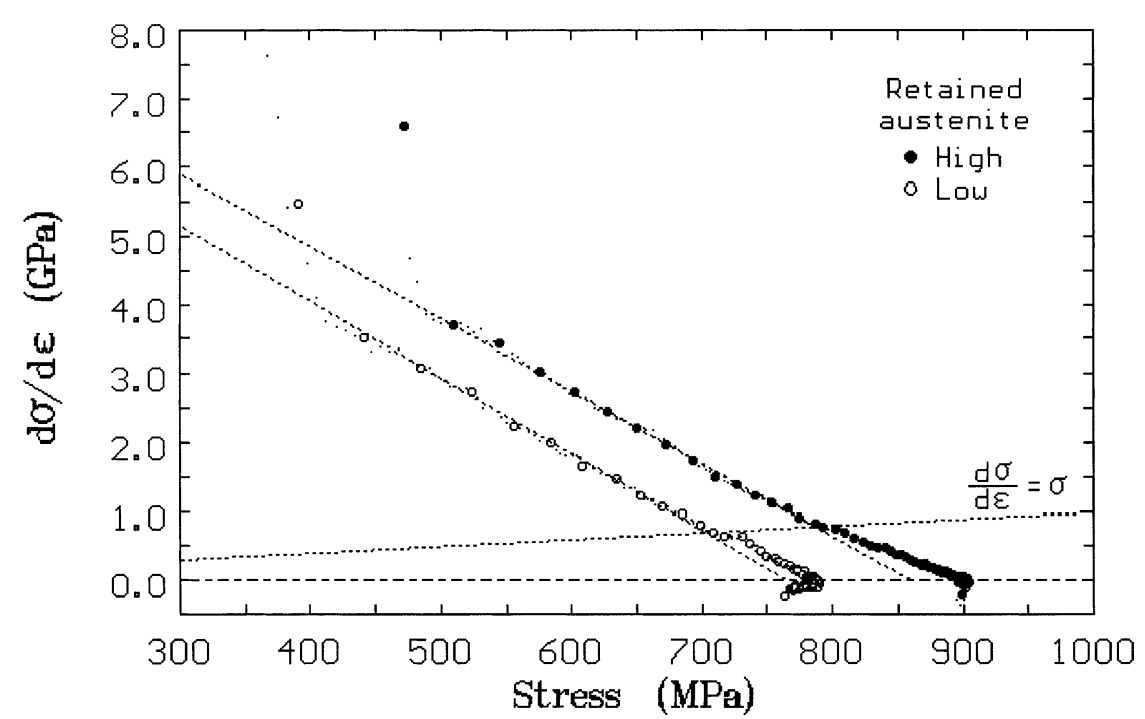

Fig. 8. Plot of the instantaneous work hardening rate as a function of stress for the materials identified as $\mathbf{A}$ and $\mathbf{G}$ in Table 1.

yielding and to overestimate it at high strains. A better prediction of strength towards high levels of strain can be obtained by means of the exponential equation proposed by Voce $^{16)}$ :

$$
\sigma=\sigma_{\mathrm{o}}+\left(\sigma_{\mathrm{s}}-\sigma_{\mathrm{o}}\right) \exp (-C \varepsilon)
$$

where $\sigma_{\mathrm{s}}$ is the saturation or steady state stress, $\sigma_{\mathrm{o}}$ the yield stress and $C$ is a coefficient that is determined from experimental data. The stress-strain curves can be fit to the relationship described by Eq. (5) by plotting the instantaneous work hardening rate $(d \sigma / d \varepsilon)$ as a function of stress. Figure 8 shows such a construction for the specimens with the lowest and highest amount of retained austenite, $\mathbf{A}$ and $\mathbf{G}$ in Table 1, where it can be seen that the samples follow the constitutive relationship given by Eq. (5), as it is possible to find a straight portion of experimental data that follows the relationship:

$$
\frac{d \sigma}{d \varepsilon}=C\left(\sigma_{\mathrm{s}}-\sigma\right)
$$

therefore, the values of $C$ and $\sigma_{\mathrm{s}}$ are obtained by fitting a straight line through the experimental data points. The linear relationship given by Eq. (6) is associated with the development of extended cross-slip, commonly known as Stage III deformation, in single crystals, ${ }^{16-18)}$ implying that any change in this relationship involves a change in the strengthening controlling mechanism. ${ }^{19)}$ The values of $d \sigma / d \varepsilon$ were calculated by fitting a succession of second degree polynomials to an even number of data points of the stress-strain curve, the procedure used in this work is described elsewhere. ${ }^{20}$ ) The broken line describing Considère's criterion, $d \sigma / d \varepsilon=\sigma^{21)}$ in Fig. 8 represents the stress at which necking would develop in tension in a strain rate insensitive material. The strain for the onset of necking $\left(\varepsilon_{\mathrm{n}}\right)$ can then be obtained by:

$$
\varepsilon_{\mathrm{n}}=\frac{1}{C} \ln \left[\frac{\sigma_{\mathrm{s}}}{\left(\sigma_{\mathrm{s}}-\sigma_{\mathrm{o}}\right)(1+C)}\right]
$$

Close examination of Fig. 8 shows that the interpolations (dotted lines) do not go through the experimental data at stresses higher than those for Considère's criterion, and this will result in the underestimation of the strength of the material towards high strains. Figure 9 shows the comparison between the experimental stress-strain curves and those predicted by Eq. (5), the parameters required in this equation were obtained from Fig. 8. It can be appreciated that the agreement of the fitted curves with the experimental data is very good at low stresses, but above a certain value of stress, the experimental curve lies above the fitted one. The experimental curve for the material with the lower amount of retained austenite (A) shows a maximum value in stress at around a strain of 0.5 , see Fig. 8, and, as a result or this, the experimental value of $\sigma_{\mathrm{s}}$ reaches the extrapolated value, see Fig. 7. It is normal practice to associate peak values of stress with mechanical instability, phenomenon associated in compression which the occurrence of shear bands, ${ }^{22-24)}$ but, no evidence of such was detected in the present samples.

One of the most common equations used to describe the stress-strain behaviour of materials tested in tension is that proposed by Hollomon in $1944,{ }^{14}$ ) which is equal to Eq. (4) without the pre-exponential yield stress term $\left(\sigma_{\mathrm{o}}\right)$. It can be demonstrated that if the material follows such a relationship, the exponent ( $n=d \ln \sigma / d \ln \varepsilon$ ) should be constant and equal to the strain at the onset of necking. Figures $\mathbf{1 0}$ and 11 show, respectively, the variation of $d \ln \sigma / d \ln \varepsilon$ with respect to either strain or stress. The dotted line in Fig. 10 corresponds to $d \ln \sigma / d \ln \varepsilon=\varepsilon$, and, as it can be seen in this figure $d \ln \sigma / d \ln \varepsilon$ varies with strain, so the data obtained should not be adjusted with the constitutive equation of the type given by Eq. (4). A small plateau is appreciated in either curve in Figs. 10 and 11, in all cases a couple of arrows indicate the extension, either in strain or stress, of such plateaux, Table 3 summarizes these data.

The presence of the plateaux mentioned above, as well as the lack of agreement between the experimental data and the curves fitted to Eq. (5), see Fig. 8, can be taken as an indication that some mechanism is enhancing the strength of the material. Figures 6 and 7 show the microstructure of 
ISIJ International, Vol. 44 (2004), No. 1

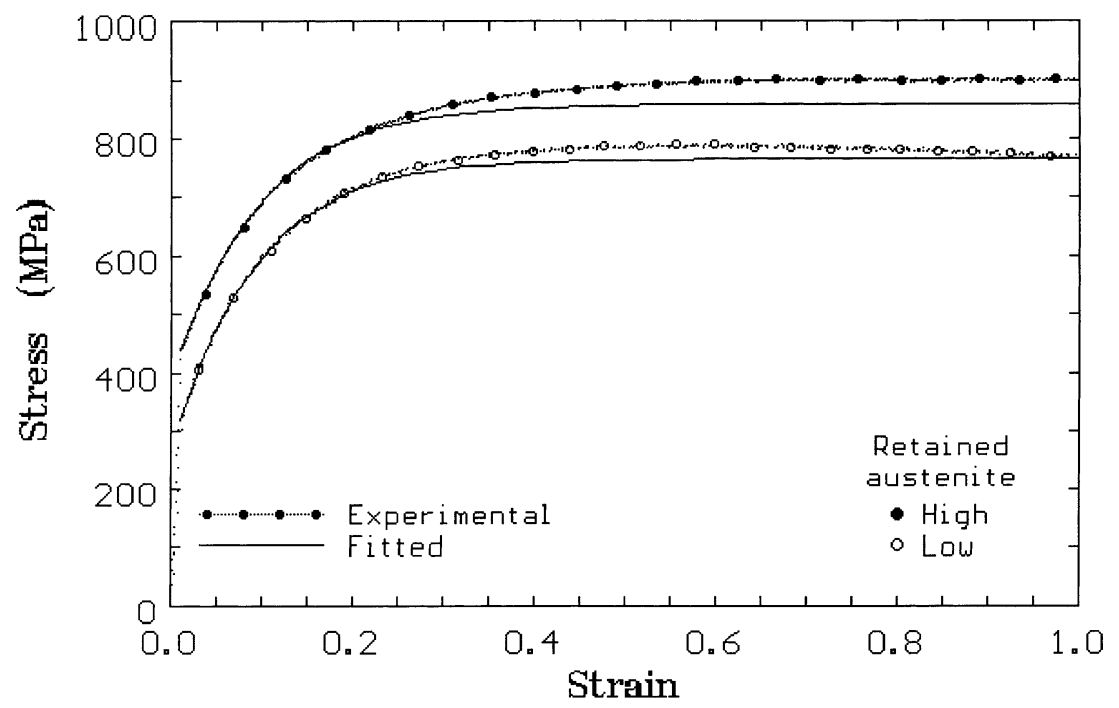

Fig. 9. Experimental and fitted stress-strain curves for the materials identified as $\mathbf{A}$ and $\mathbf{G}$ in Table 1.

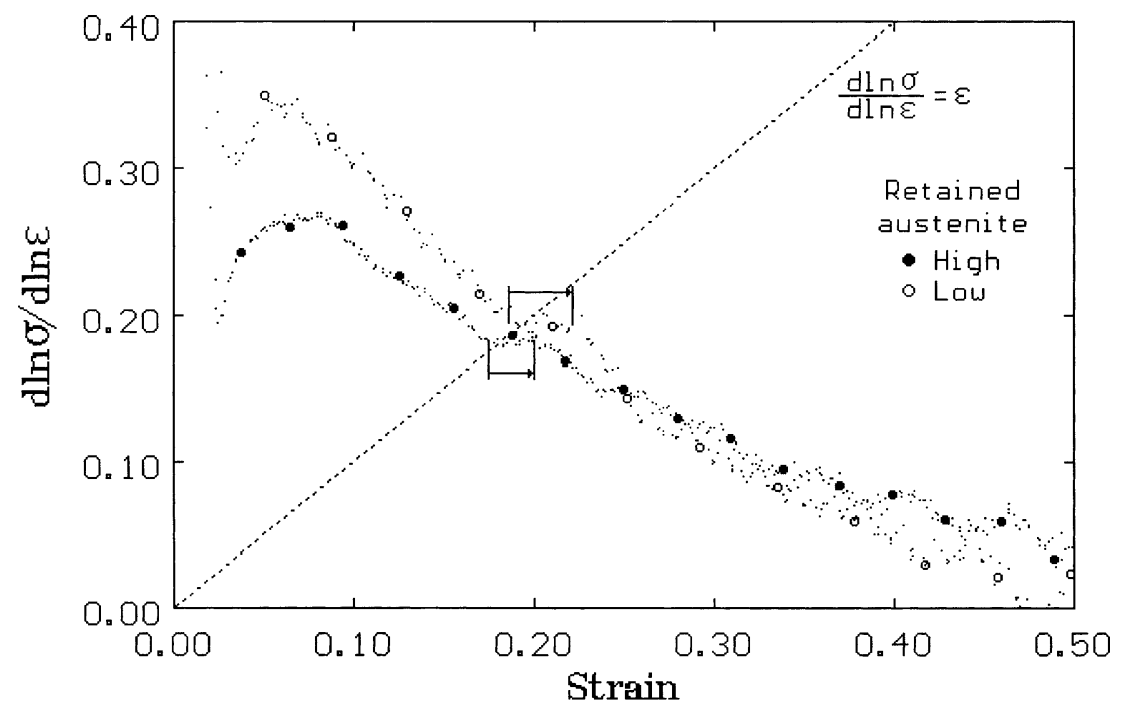

Fig. 10. Variation of $d \ln \sigma / d \ln \varepsilon$ with respect to the strain for the experimental curves of Fig. 8, the dotted line $d \ln \sigma / d \ln \varepsilon=\varepsilon$ is normally associated with the onset of necking in tensile tests.

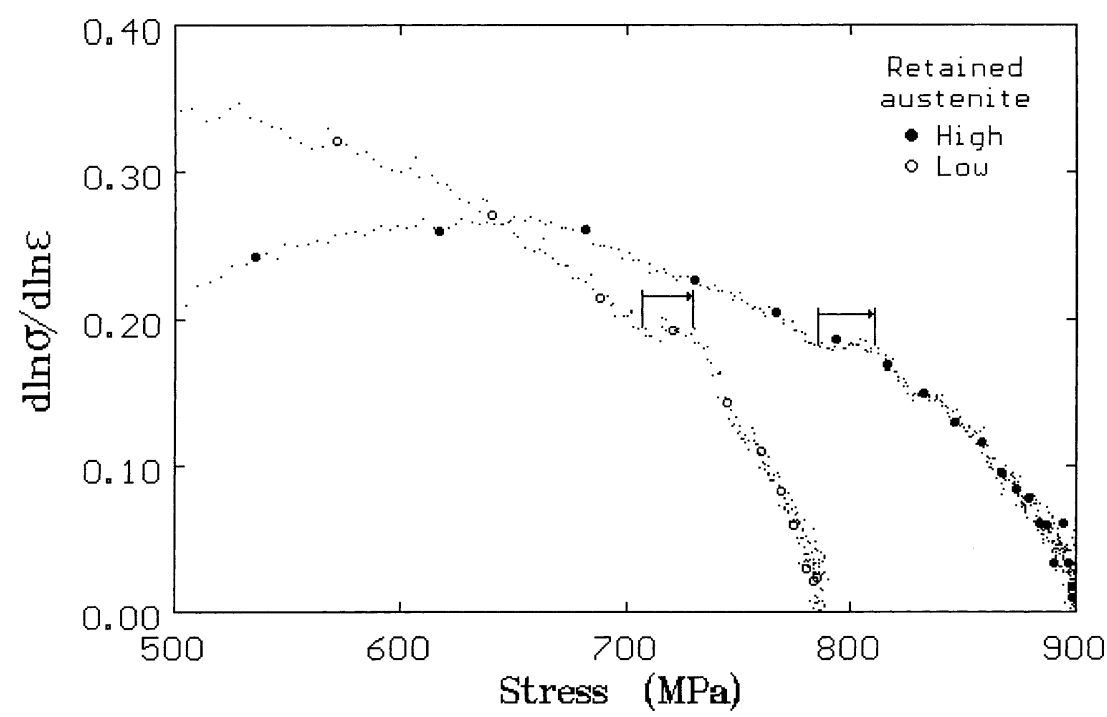

Fig. 11. Variation of $d \ln \sigma / d \ln \varepsilon$ with respect to the stress for the experimental curves of Fig. 8 . 
Table 3. Parameters deduced from the analysis of the stress-strain curves of samples with high and low amounts of retained austenite.

\begin{tabular}{cccccccr}
\hline Sample & \multicolumn{3}{c}{ Parameters in Eq. (4) } & \multicolumn{2}{c}{ Strain } & \multicolumn{2}{c}{ Stress (MPa) } \\
identification & $\sigma_{0}(\mathrm{MPa})$ & $\sigma_{\mathrm{s}}(\mathrm{MPa})$ & $\mathrm{C}$ & start & end & start & end \\
\hline $\mathbf{A}$ & 265 & 765 & 0.090 & 0.186 & 0.221 & 702 & 730 \\
$\mathbf{G}$ & 390 & 860 & 0.095 & 0.175 & 0.200 & 785 & 810 \\
\hline \multicolumn{2}{l}{ The start and end of strain and stress correspond to the plateaux of Figures 9 and 10.}
\end{tabular}

sample $\mathrm{G}$ before and after deformation to an equivalent strain of one. The microstructures consist in a ferritic matrix that surrounds the retained austenite and bainite, identified by means of LOM due to their reaction to the tint etchant used ${ }^{7,8)}$ which are resistant to the etchant used in this work. ${ }^{25)}$ These images can be used to explain the mechanical behaviour of the material. It can be considered that the heat treated material consists of a mixture of ferrite, retained austenite, bainite, and traces, if any, of martensite (Figs. 6(a) and 6(b), and 7(a)). It can be considered that, due to the relative strength of the different microstructural constituents, ferrite will deform to a greater extend than any of the other structures as strain progresses, and, at the same time, some of the retained austenite will be able to transform into martensite, augmenting the strength of the material. It is only when deformation has accumulated in ferrite, increasing its strength to the level that it cannot sustain any more homogeneous deformation, that the TRIP-effect is triggered in austenite, with the consequent increase of strength and work hardening rate $(d \sigma / d \varepsilon)$ observed in Figs. 8 to 11 .

Figures 6(c) and 6(d), and 7(b) indicate that most of the deformation is carried out by the soft ferrite, i.e. the shape changes in the zones of ferrite are bigger, as the harder structures like bainite and retained austenite are separated following the direction of plastic flow. It seems that austenite first rotates, while ferrite deforms, and later on, part of the retained austenite transforms to martensite. These observations were confirmed by the decrease in the IQ factor for ferrite in deformed specimens as it can be seen in Fig. 7(b) where the regions in which ferrite is detected are darker than when undeformed, see Fig. 7(a).

Close examination of Figs. 9 to 11, together with the data shown in Table 3, can help to understand the effect of changing the amount of initial retained austenite with equal carbon content. The effect of increasing the amount of retained austenite seems to result in triggering the TRIP effect at lower strains, but higher stresses ( 0.175 and 785 $\mathrm{MPa}$ in comparison to 0.186 and $702 \mathrm{MPa}$, when changing from 9.11 to $5.70 \%$ ). The maximum strength that can be achieved by the material depends in the amount of retained austenite in the undeformed material, as the sample with the higher amount of such phase will reach close to 900 $\mathrm{MPa}$, whereas the one with the lower amount only reached $780 \mathrm{MPa}$.

\section{Conclusions}

In this work an analysis of the TRIP-effect has been implemented by means of series of axisymmetric compressive tests on different multi-phase structures of a $\mathrm{Si}-\mathrm{Mn}$ bearing TRIP-assisted steel, which contain retained austenite from
5.70 to $9.11 \%$. The results show that the axisymmetric compression test is a powerful tool to investigate the transformation stability of the retained austenite in low alloyed TRIP-assisted steels, giving a possibilities for controlled loading up to high levels of the true strain.

The high strains achieved by axisymmetric compression testing allowed for a deeper analysis in relation with the nature of the constitutive equations, and, from them, it was possible to found the point at which the TRIP-effect is triggered.

The behaviour of the material with about the same carbon content of the retained austenite was affected only by the amount of retained austenite. Under the above-mentioned conditions it was found that the TRIP-effect was triggered at lower strains, but higher stresses, as the amount of this phase increased. The maximum strength of the material seems to be related with the content of retained austenite in undeformed conditions.

\section{Acknowledgements}

RC acknowledges the support provided by CONACYT, Mexico.

\section{REFERENCES}

1) V. F. Zackay, E. R. Parker, D. Fahr and R. Bush: Trans. Am. Soc. Met., 60 (1967), 252.

2) J. B. Leblond, J. Devaux and J. C. Devaux: Int. J. Plast., 5 (1989), 551.

3) F. Marketz and F.D. Fisher: Metall. Mater. Trans., 26A (1995), 267.

4) M. De Meyer, D. Vanderscheren and B. C. De Cooman: ISIJ Int., 39 (1999), 813.

5) P. J. Jacques, J. Ladriére and F. Delannay: Metall. Mater. Trans., 32A (2001), 2759.

6) A. Airod, H. Vandekinderen, J. Barros, R. Colás and Y. Houbaert: $J$. Mater. Process. Technol., 134 (2003), 398.

7) F. S. LePera: J. Met., 32 (1980), No. 3, 38.

8) E. Girault, P. Jacques, Ph. Harlet, K. Mols, J. van Humbeeck, E. Aernoudt and F. Delannay: Mater. Charact., 40 (1998), 111.

9) S. I. Wright, B. L. Adams and K. Kunze: Metall. Trans. A, 24A (1993), 819.

10) B. D. Cullity: Elements of X-Ray Diffraction, 2nd Ed., AddisonWesley, NY, (1978), 508.

11) R. C. Ruhl and M. Cohen: Trans. TSM-AIME, 245 (1969), 241.

12) D. J. Dyson and B. Holmes: J. Iron Steel Inst., 208 (1970), 469.

13) P. Ludwik: Elemente der Technologischen Mechanik, SpringerVerlag OHG, Berlin, (1909), 1.

14) J. H. Hollomon: Trans AIME, 162 (1945), 268.

15) J. Datsko: Material Properties and Manufacturing Processes, J. Wiley \& Sons, Inc., New York, (1966), 127.

16) U. F. Kocks, A. S. Argon and M. F. Ashby: Thermodinamics and Kinetics of Slip, Progress in Materials Science, Vol. 19, Pergamon Press, Oxford, (1975), 135.

17) H. Mecking, B. Nicklas, N. Zarubova and U.F. Kocks: Acta Metall., 34 (1986), 527.

18) L. Kaps and F. Haeßner: Plasticity of Metals: Experiments, Models, Computation, ed. by E. Steck, R. Ritter, U. Peil and A. Ziegenbein, Wiley-VCH, Weinheim, (2001), 1.

19) R. Colás: Scr. Metall., 19 (1985), 155

20) R. L. Burden and J. D. Faires: Numerical Analysis, 6th Ed., PWS Pub. Co., Boston, (1978), 258.

21) A. Considère: Ann. Ponts. Chau., 9 (1885), 574

22) J. J. Jonas, R. A: Holt and C. E. Coleman: Acta Metall., 24 (1976), 911.

23) R. Colás and A. Grinberg: Mater. Sci. Eng. A, A112 (1889), 49.

24) R. Colás and A. Grinberg: Mater. Sci. Eng. A, A161 (1893), 201

25) T. Ros-Yáñez, Y. Houbaert and A. Marten: Mater. Charact., 47 (2001), 93. 